\title{
Results of nerve grafting in radial nerve injuries occurring proximal to the humerus, including those within the posterior cord
}

\author{
Jayme Augusto Bertelli, MD, PhD, and Marcos Flávio Ghizoni, MD, MSc \\ Department of Neurosurgery, Southern University of Santa Catarina [Unisul], Avenida José Acácio Moreira, Tubarão, Brazil
}

OBJECTIVE Results of radial nerve grafting are largely unknown for lesions of the radial nerve that occur proximal to the humerus, including those within the posterior cord.

METHODS The authors describe 13 patients with proximal radial nerve injuries who were surgically treated and then followed for at least 24 months. The patients' average age was 26 years and the average time between accident and surgery was 6 months. Sural nerve graft length averaged $12 \mathrm{~cm}$. Recovery was scored according to the British Medical Research Council (BMRC) scale, which ranges from M0 to M5 (normal muscle strength).

RESULTS After grafting, all 7 patients with an elbow extension palsy recovered elbow extension, scoring M4. Six of the 13 recovered M4 wrist extension, 6 had M3, and 1 had M2. Thumb and finger extension was scored M4 in 3 patients, M3 in 2, M2 in 2, and M0 in 6.

CONCLUSIONS The authors consider levels of strength of M4 for elbow and wrist extension and M3 for thumb and finger extension to be good results. Based on these criteria, overall good results were obtained in only 5 of the 13 patients. In proximal radial nerve lesions, the authors now advocate combining nerve grafts with nerve or tendon transfers to reconstruct wrist, thumb, and finger extension.

http://thejns.org/doi/abs/10.3171/2014.12.JNS141944

KEY WORDS radial nerve palsy; nerve grafting; nerve transfer; neurotization; peripheral nerve

$\mathrm{T}$ HE radial nerve innervates muscles responsible for elbow, wrist, and thumb/finger extension, with triceps innervation originating high in the axilla. ${ }^{8} \mathrm{We}$ define proximal lesions of the radial nerve as injuries proximal to the humerus, including lesions within the posterior cord. All patients present with paralysis of wrist, thumb, and finger extension. Elbow extension is either preserved or not, depending on whether the site of injury is proximal or distal to the latissimus dorsi tendon where the first branch to the triceps-which innervates the triceps long head-originates.

Radial nerve grafting has been associated with good results. However, the initial excellent results obtained by Millesi $^{23}$ have not been reproduced in other series. ${ }^{24}$ On the British Medical Research Council (BMRC) scale, Millesi ${ }^{23}$ obtained an M5 level of recovery in $43 \%$ of his 38 patients. Recent series of radial nerve grafting at the arm level have generated variable outcomes, but less than ideal results. ${ }^{1,6,26,31,34,37}$ If, on the one hand, a large body of literature is available documenting the results of radial nerve grafting at the arm level, on the other hand, results of grafting for proximal lesions are largely unknown. Proximal injuries of the radial nerve are associated with high-energy trauma and humeral fractures, portending worse outcomes. ${ }^{20,30}$ Very few reports have addressed proximal lesions of the radial nerve, ${ }^{26,31,34}$ and none have separated postgraft strength recovery results for elbow, wrist and finger extension.

In the present paper, we report the outcomes in a series of 13 consecutive patients with proximal lesions of the radial nerve who underwent reconstructive surgery over a 3 -year period.

\section{Methods}

Between 2009 and 2012, 13 male patients with a mean age of 26 years (range 17-37 years), all with proximal radial nerve lesions as a result of a motorcycle accident, underwent surgery at our institution at a mean of 6 months postinjury (range 4-9 months). Among these 13 patients, 7 had bone injuries. Among those without fractures, $2 \mathrm{had}$

ABBREVIATIONS BMRC = British Medical Research Council; FDS = flexor digitorum superficialis; ECRB = extensor carpi radialis brevis; ECRL = extensor carpi radialis longus; EDC = extensor digitorum communis; EPL = extensor pollicis longus; FCR = flexor carpi radialis; FCU = flexor carpi ulnaris; FDS = flexor digitorum superficialis; PIN = posterior interosseous nerve; $\mathrm{PL}=$ palmaris longus.

ACCOMPANYING EDITORIAL See pp 175-178. DOI: 10.3171/2015.1.JNS142802.

SUBMITTED August 21, 2014. ACCEPTED December 9, 2014.

INCLUDE WHEN CITING Published online August 14, 2015; DOI: 10.3171/2014.12.JNS141944. 
shoulder dislocation and 4 had stretch injuries of the infraclavicular brachial plexus. Seven patients had triceps paralysis, in addition to paralysis of wrist, thumb, and finger extension. Six had a humeral fracture that required open reduction and internal fixation with plates and screws. One patient had clavicular nonunion that was repaired during the same operation as nerve reconstruction. Five of the 13 patients presented with associated injuries of other nerves, including the suprascapular nerve, lateral cord, and median nerve (Table 1). The ulnar nerve was preserved in every case.

With the patient under general anesthesia without muscle relaxants, the distal stump of the radial nerve was initially explored via an incision on the lateral arm, while the proximal stump was approached by means of an incision on the upper third of the medial aspect of the arm (Fig. 1). The distal cable was dissected proximally, while the proximal cable was tracked distally to decrease graft length (Fig. 2). The distal stump was transposed medially and subcutaneously in front of the distal third of the biceps. Nerve stumps were trimmed and the nerve gap was grafted using the sural nerve (Fig. 3). Graft length averaged $12.5 \mathrm{~cm}(\mathrm{SD} \pm 2.8 \mathrm{~cm})$. Nerve coaptation was performed using 9-0 monofilament sutures. In 3 patients after proximal and distal stump transposition, when the distal cable was short, a third 2-cm-long incision was necessary for microsurgical coaptation of the grafts with the distal stump (Fig. 4). In 7 patients with triceps palsy and associated nerve injuries, surgery began with radial nerve dissection in the upper arm, followed by proximal dissection of the brachial plexus after detaching the pectoralis major muscle, which by the end of surgery was reinserted (Figs. 5 and 6). In 4 patients we needed to approach the plexus in the supraclavicular region, connecting the grafts to the posterior division of the upper trunk, plus/minus the middle trunk (Figs. 7 and 8; Cases 4, 7, 8, and 11 in Table 1). In all patients with triceps palsy, nerve grafts were attached proximal to the origin of the triceps branches.

After surgery, all patients used an arm sling for 1 week. If the pectoralis major had been deinserted and reinserted, an arm sling was used for 3 weeks.

Postoperatively, patients were followed for at least 24 months. The average time to the final postoperative assessment was 35.5 months ( $\mathrm{SD} \pm 12.5$ months). At final evaluation, patients underwent manual strength testing of elbow, wrist, thumb, and finger extension, which was scored using the 5-point BMRC scale (5/5, normal; $0 / 5$, absent). ${ }^{33}$

We divided our patients into 2 groups to test for the influence of graft length and a longer time to final postoperative evaluation on the outcomes. We allocated those patients who achieved M4 wrist extension and either M3 or M4 thumb, and finger extension into Group 1. We allocated patients with worse outcomes into Group 2. The mean postoperative evaluation interval (months) and graft length $(\mathrm{cm})$ were calculated for Groups 1 and 2 and compared using nonpaired Student t-tests; $\mathrm{p}<0.05$ was considered a statistically significant intergroup difference.

\section{Results}

After grafting, all 7 patients with elbow extension palsy recovered elbow extension, scoring M4 for muscle strength. Six of the 13 patients recovered wrist extension at the M4 level, 6 at the M3 level, and 1 at M2. Thumb and finger extension scored M4 in 3 patients, M3 in 2, M2 in 2, and M0 in 6. Patient pre- and postoperative data are summarized in Table 1.

Patients in Group 1, those with good outcomes, had a mean graft length and postoperative interval of $10.6 \mathrm{~cm}$ $(\mathrm{SD} \pm 1.6 \mathrm{~cm})$ and 37 months (SD \pm 14 months), respectively. These values were not statistically different $(\mathrm{p}<$ $0.05)$ than corresponding means for Group 2, which were $13.6 \mathrm{~cm}(\mathrm{SD} \pm 2.9 \mathrm{~cm})$ and 35 months (SD \pm 12 months).

\section{Discussion \\ Patient Characteristics}

Six of our patients had radial nerve lesions within the posterior cord. We included these patients in our study because our goal in all patients was to reconstruct function by means of nerve grafts connecting interrupted radial nerve fibers to the radial nerve itself, using sural nerve grafts. Variations in the site of nerve injury were determined by where we identified a healthy proximal stump, which in all cases was found proximal to the medial border of the humerus. These lesions differ from those at the arm level, because longer distances mean that axons have not regenerated enough to reinnervate wrist, finger, and thumb extensors. Pan et al. ${ }^{26}$ followed the same principle and classified these injuries to the radial nerve and posterior cord as Level I infraclavicular radial nerve injuries, with the site of actual injury occurring somewhere between the clavicle and the entrance of the spiral groove of the humerus.

Even though all our patients had a radial nerve injury proximal to the humerus, not all exhibited triceps palsy. This can be explained because of the proximal origin of the motor branch to the triceps long head, around the latissimus dorsi tendon. Roughly $8 \mathrm{~cm}$ separate the origin of the triceps long head motor branch from the humerus medial border. ${ }^{8}$ Because this motor branch does not traverse the spiral groove, it may be protected from the stretch injury that commonly occurs with fractures of the humerus.

Ideally, all patients with radial nerve lesions should undergo grafting as early as possible, preferably within 3 months, and not longer than 12 months after the injury. Our patients underwent surgery an average of 6 months postinjury. They were not treated with surgery earlier because of multiple injuries, late referral, or socioeconomic issues.

\section{Nerve Grafting}

In our series of 7 patients with triceps palsy, elbow extension reconstruction was predictably restored to an M4 strength level after nerve grafting from either the posterior division of the upper trunk or the posterior cord.

Wrist extension also was predictably restored by grafting. However, half of the patients only recovered M3 strength, which is not adequate for proper wrist function. When grasping an object, a patient with only M3 wrist extension loses that extension because the weight of the object overcomes it; consequently, the wrist drops, and the patient ultimately loses his grasp. With wrist flexion, 


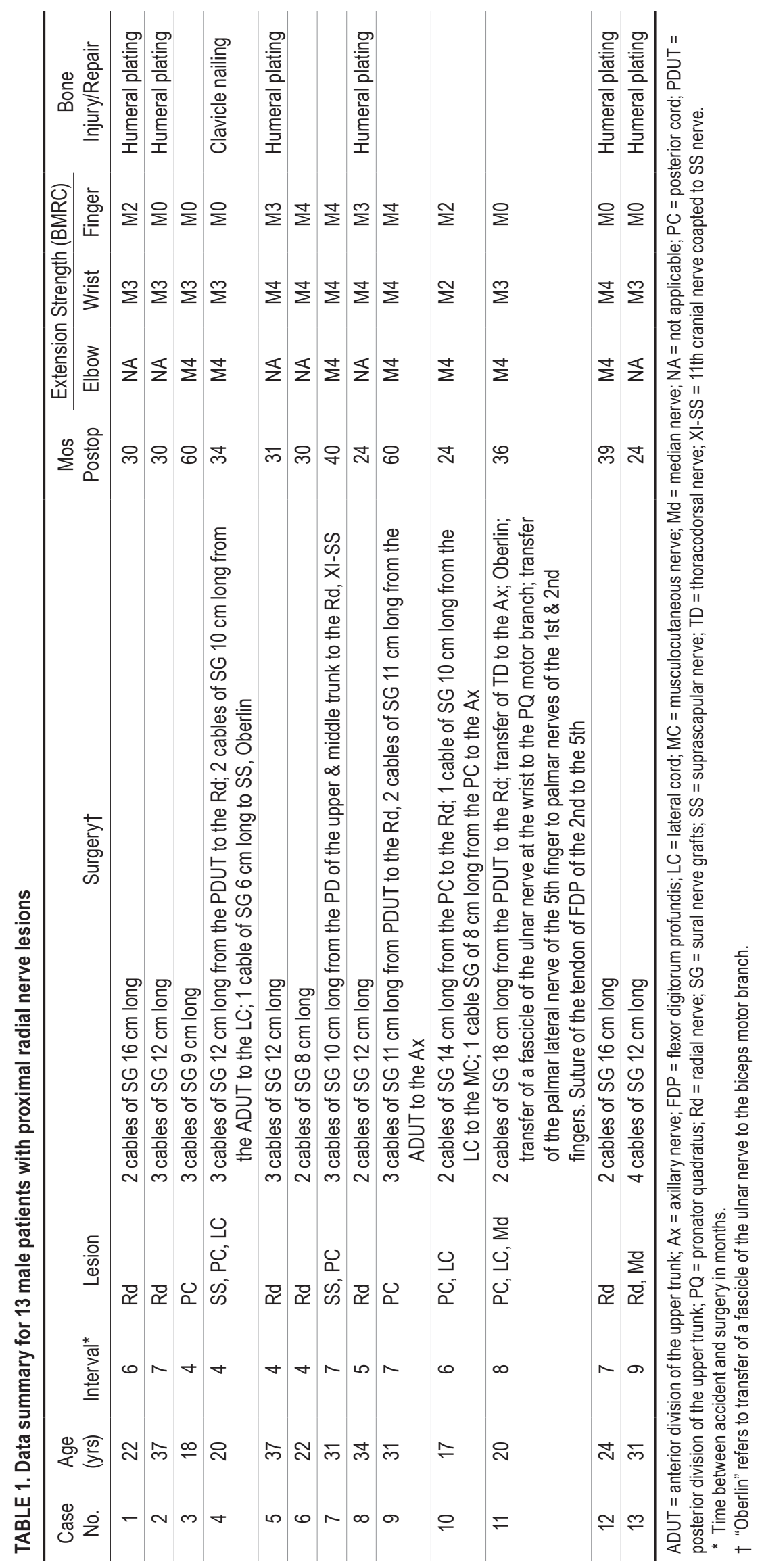




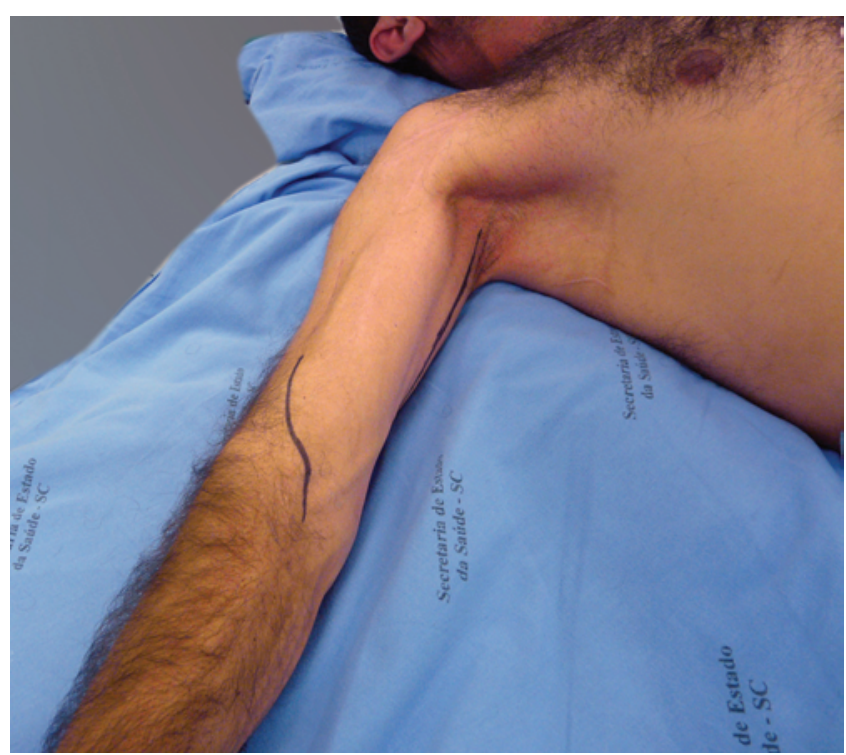

FIG. 1. Photograph of the right upper limb depicting the double approach for grafting a radial nerve lesion. Figure is available in color online only.

grasp strength decreases by $60 \% .{ }^{21}$ Patients need at least M4 strength in their wrist extensors to maintain the wrist in an extended or neutral position while grasping an object to lift it. Following a radial nerve anesthetic block and evaluation of grip and wrist extension strength during the recovery period, Suzuki et al. ${ }^{36}$ determined that recovery of half-normal wrist extension strength correlates with $70 \%$ of grasp strength, which prevents wrist flexion during maximal grasping. In our opinion, M3-level strength cannot be considered a good result for wrist extension reconstruction, as reported elsewhere. . $^{2,31,34}$

Concerning thumb and finger extension, M3 is adequate power to function, because patients just need to spread their fingers apart slightly to grasp something; there is no need for strength because no motion is performed against resistance. In addition, by flexing the wrist, the finger span can be augmented via a tenodesis effect to compensate for limited recovery of active range of motion. However, even

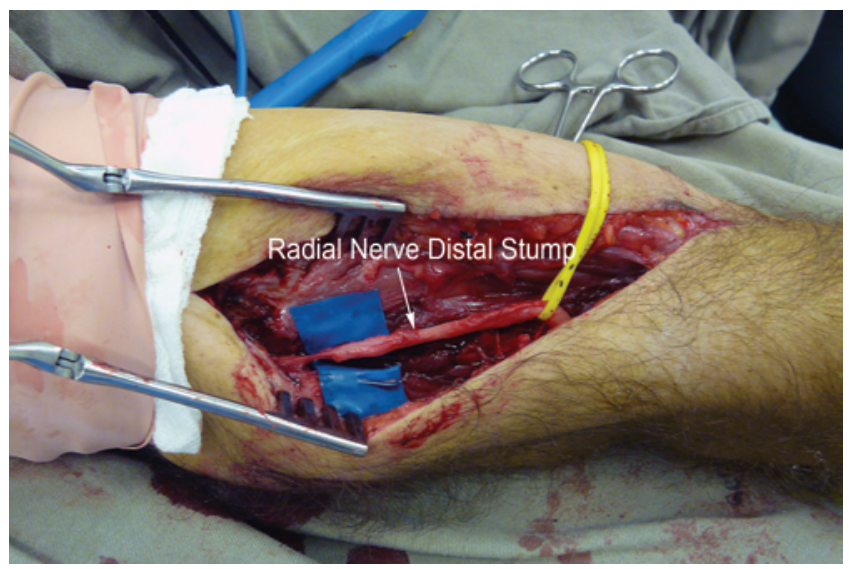

FIG. 2. Intraoperative view of the dissected distal stump. Dissection was carried out from distal to proximal to achieve maximal length for the distal stump and thereby reduce sural graft length. Figure is available in color online only.

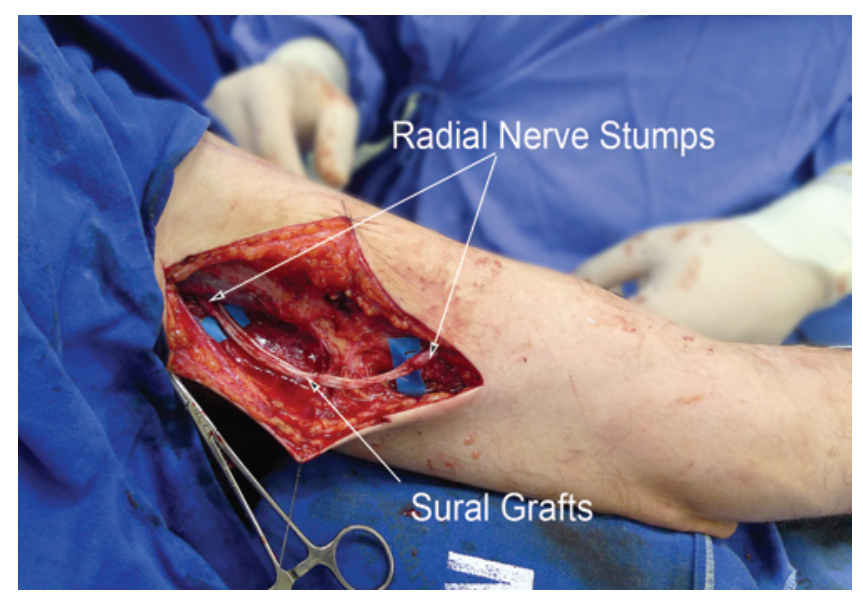

FIG. 3. Intraoperative view of the dissection on the medial aspect of the upper arm showing sural grafting of the radial nerve. The distal stump of the radial nerve was medially transposed. Figure is available in color online only.

considering M3 to be a good result, only 5 of our 13 patients benefited from radial nerve grafting.

We obtained M4 wrist and thumb/finger extension in 2 patients who had no humeral plating (for repair of fracture) or associated injuries of the median or musculocutaneous nerve. Among the 6 patients who underwent humeral plating, only 1 recovered active thumb and finger extension. Combined nerve injuries and humeral fractures may be associated with more severe injuries, which may explain worse outcomes in these patients.

The length of sural grafts varied significantly across the 13 patients. However, when we compared graft length between patients with a good (Group 1) versus inadequate (Group 2) outcome, graft length was similar. The duration of our postoperative follow-up was not homogeneous because our goal was to have a minimum of 24 months of follow-up for all patients. However, when we compared patients with (Group 1) and without (Group 2) good outcomes, there also was no difference in the postoperative

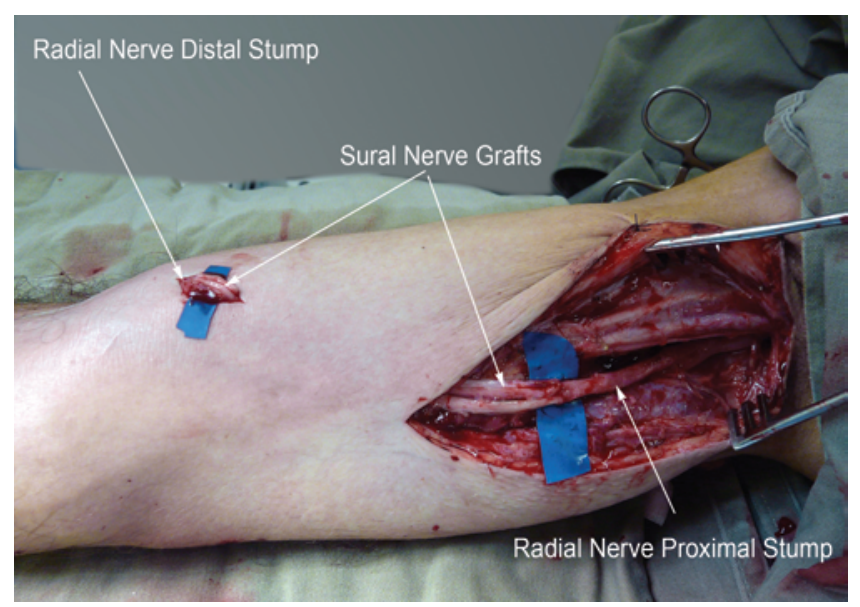

FIG. 4. Intraoperative view of the dissection on the medial aspect of the upper arm showing sural grafting of the radial nerve. After medial transposition of a short distal stump of the radial nerve, a third incision over the distal part of the biceps was needed to complete nerve coaptation. Figure is available in color online only. 


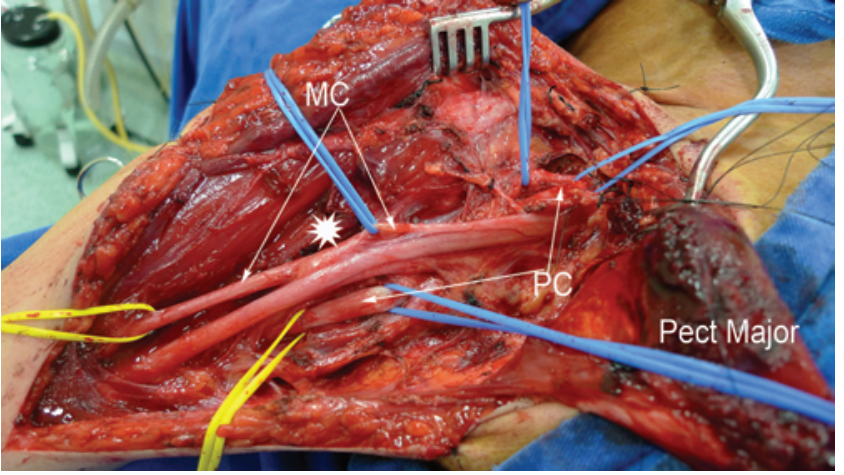

FIG. 5. Intraoperative view of dissection of the infraclavicular brachial plexus on the right side. The pectoralis (Pect) major muscle was detached. Note the star indicating a lesion on the musculocutaneous nerve (MC), which in this patient stems directly from the median nerve. The posterior cord (PC) also was injured at this level. Figure is available in color online only.

interval before final evaluation. Recognizing the limitations resulting from the small number of patients, it seems that graft length and longer postoperative follow-up did not influence outcomes.

Among the 13 patients, 5 had adequate results (i.e., wrist extension scoring M4 and thumb and finger extension scoring M3 or M4); these patients did not request additional surgery. Tendon transfers were performed in 3 patients for thumb and finger extension reconstruction. A free gracilis muscle was reinnervated by the pronator quadratus motor branch in 2 patients to enhance wrist extension. Three patients have not yet undergone secondary procedures.

Shergill et al. ${ }^{34}$ defined high radial nerve injuries as those that occur proximal to the triceps branches. They defined good results as elbow extension scoring M4 or better, and wrist extension scoring M3 or better. They observed 4 good results in their 21 repairs. Using these criteria, 6 of our 7 patients with both a radial nerve and triceps palsy experienced a good result. After repair of 10 missile injuries of the proximal radial nerve, Roganovic and Petkovic ${ }^{31}$ concluded that nerve grafting is ineffective, with none of their patients recovering any more than

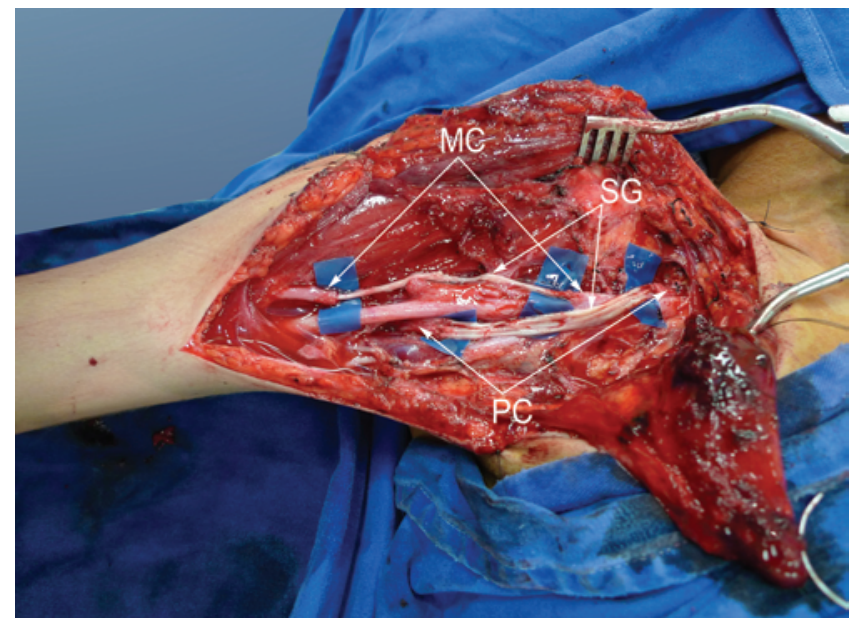

FIG. 6. Same patient shown in Fig. 5, after grafting. SG = sural nerve graft. Figure is available in color online only.

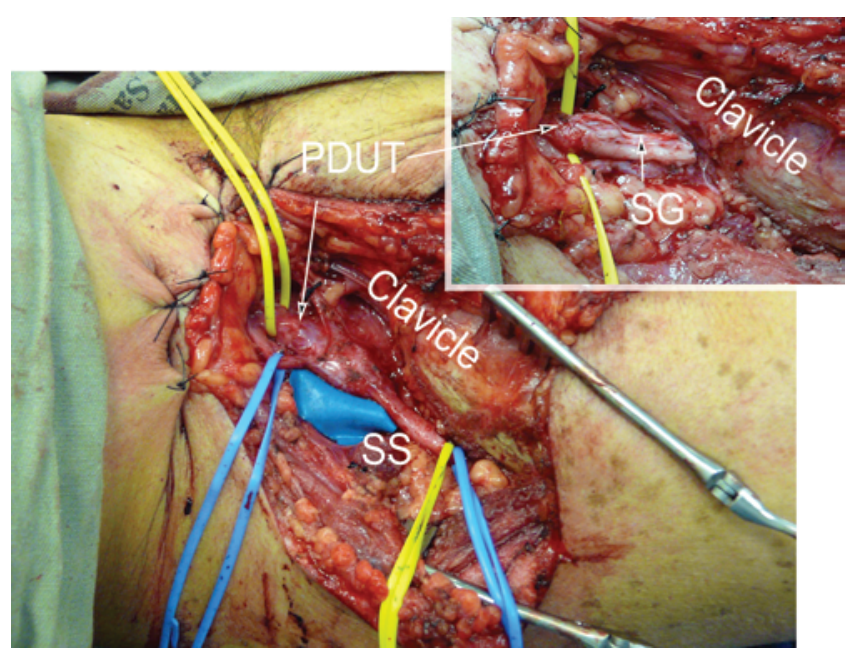

FIG. 7. Case 7 (see Table 1). Intraoperative view of dissection of the right supraclavicular region showing injury to the posterior division of the upper trunk (PDUT) and to the suprascapular nerve (SS). In the inset, note sural grafts coapted to the PDUT. Figure is available in color online only.

M3 strength. Unfortunately, it is not clear if the extension strength that was recovered was at the elbow, at the wrist, in the thumb and fingers, or in some combination. Pan et al. ${ }^{26}$ reported on 39 patients with proximal lesions of the radial nerve, but failed to distinguish between M3- and M4-level recovery. They reported achieving M3 or better recovery of wrist extension in $80 \%$ of their patients; however, only $30 \%$ of their patients experienced the same degree of recovery in thumb or finger extension.

Ninety percent of our patients achieved wrist extension scores of M3 or better, and 40\% scored M3 or better

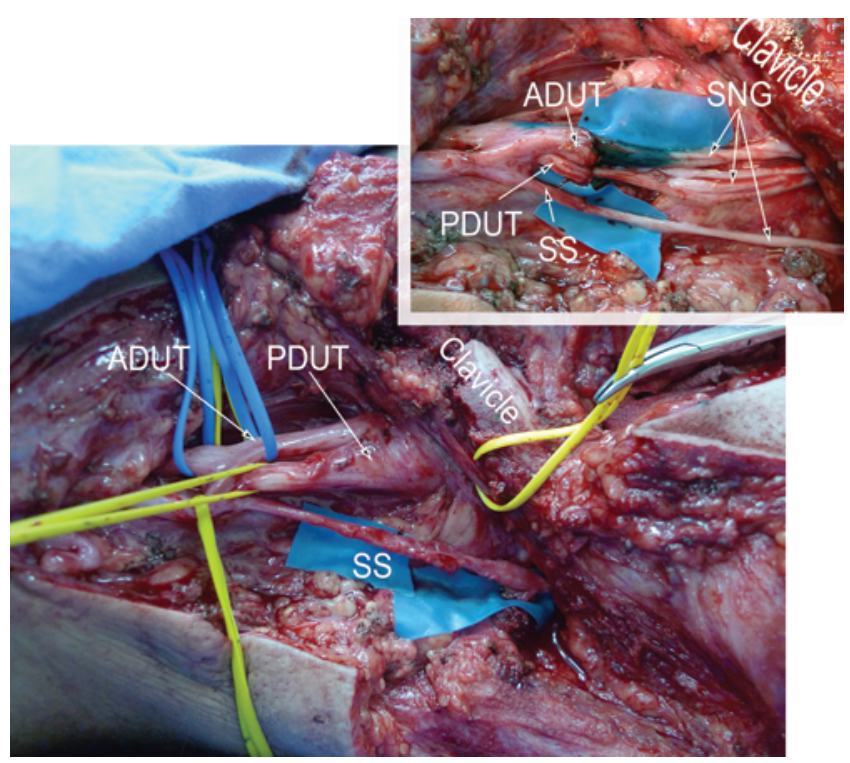

FIG. 8. Case 4 (see Table 1). Intraoperative view of dissection of the right supraclavicular region showing injury to the posterior division of the upper trunk and to the suprascapular nerve. In the inset, note the anterior division of the upper trunk (ADUT) grafted to the lateral cord. The posterior division of the upper trunk plus the posterior branch of the middle trunk were grafted to the posterior cord. The suprascapular nerve was grafted using a sural nerve graft (SNG). Figure is available in color online only. 
on thumb and finger extension. Despite the overall better results we observed in our series relative to the abovementioned reports, we judge our results to be less than ideal because of the limited recovery of strength in wrist, thumb, and finger extension.

\section{Alternatives to Nerve Grafts}

In patients in whom it is difficult to access the proximal stump of the radial nerve or the posterior cord because of scarring, open lesions, or vascular injuries, nerve transfers are a viable alternative to restore triceps function. Not infrequently with a posterior cord lesion, latissimus dorsi innervation is preserved and direct transfer of the thoracodorsal nerve can predictably restore elbow extension. ${ }^{35}$ Transfer of the nerve to the brachialis for triceps reconstruction has been reported by Bertelli and Ghizoni ${ }^{6}$ in a patient with spinal cord injury. Transfer of fascicles of the ulnar nerve to triceps branches also has been reported to restore elbow extension. ${ }^{15,27}$ However, if a fascicle to the flexor carpi ulnaris (FCU) is used, the FCU may be weakened and unsuitable for tendon transfer for thumb and finger extension reconstruction in the future. The medial pectoral, phrenic, and 11th cranial nerves have been used for elbow extension reconstruction with variable results; however, to selectively reinnervate the triceps, a nerve graft was needed. ${ }^{14,16}$ Intercostal nerve transfers to triceps motor branches are successful in only about half of patients. ${ }^{17}$

Nerve transfers typically restore M4 wrist extension strength in patients with either a radial or brachial plexus palsy, and should be seriously considered for proximal lesions of the radial nerve, because grafting alone has yielded less than ideal results in our experience. Motor branches to the pronator teres, ${ }^{18}$ quadratus, ${ }^{9}$ and flexor digitorum superficialis (FDS) ${ }^{29}$ have been successfully used to reinnervate the extensor carpi radialis brevis (ECRB) and the extensor carpi radialis longus (ECRL). Because the pronator teres ${ }^{11}$ and $\mathrm{FDS}^{7,32}$ might be used as tendon transfers for wrist and finger extension reconstruction, we prefer to use the motor branch of the pronator quadratus. We believe that combining radial nerve grafting with a distal nerve transfer for reinnervation of the ECRB is valid, because grafts can reinnervate the ECRL, thereby increasing wrist power.

For thumb and finger extension reconstruction in radial nerve palsies, the motor branch of the flexor carpi radialis (FCR) has been used to reinnervate the posterior interosseous nerve (PIN). ${ }^{12,18}$ García-López et al. ${ }^{18}$ reported M3 or better results in all 5 of their patients with radial nerve lesions. However, Ray and Mackinnon ${ }^{29}$ observed a less than ideal recovery in 7 of their 19 patients. Sacrificing the FCR is not without problems. If surgery fails for some reason, the only remaining option for thumb and finger extension reconstruction would now be tendon transfer of the FCU to the extensor digitorum communis (EDC) and extensor pollicis longus (EPL). In this situation, independent motion of thumb and finger extension cannot be restored. In radial nerve palsies, the palmaris longus (PL) is traditionally used to independently reanimate the thumb. ${ }^{2}$ However, in cases of failed FCR motor nerve transfer with secondary transfer of the FCU tendon for thumb and finger extension reconstruction, the PL must be left undisturbed to preserve at least 1 wrist flexor. If all wrist flexors are sacrificed, when patients extend their fingers their wrist will extend concomitantly and involuntarily. In addition, the results of tendon transfers for thumb and finger extension are enhanced when the wrist can be actively flexed to $20^{\circ}{ }^{2}$ Another point to consider is that the PL is absent in one-third of individuals..$^{10}$ In such individuals, use of the FCR motor branch as a donor for nerve transfer is contraindicated, because this will prevent any FCU tendon transfer to the EDC if nerve repair fails.

Tendon transfers for radial nerve palsy consistently produce good results. ${ }^{2,11,22,32}$ It is possible that successful nerve transfers might provide better results than tendon transfers via more natural motion reconstruction and increased range of motion. However, for the moment the use of tendon transfers for the reconstruction of thumb and finger extension seems more reliable than the transfer of the FCR motor branch to the PIN. Nerve transfers have reliably restored thumb and finger extension when the nerve to the supinator is transferred to the PIN, with 1 partial failure in 21 treated patients with spinal cord or brachial plexus palsy. ${ }^{3,7,38}$ However, in radial nerve palsy, the nerve to the supinator muscle is paralyzed and unavailable for transfer. The question is not whether nerve transfers provide reliable results for thumb and finger extension reconstruction, but whether the FCR is the best donor nerve. Further studies are needed to clarify this issue.

Combining strategies to reconstruct proximal radial nerve or posterior cord lesion palsies has recently been described. Oberlin et al. ${ }^{25}$ reported using nerve transfers for triceps palsy reconstruction and tendon transfers for wrist/thumb and finger extension reconstruction. Bertelli and Ghizoni ${ }^{4}$ and Plate et al. ${ }^{28}$ have reported combining a nerve graft and distal nerve transfer for wrist extension reconstruction. In proximal radial nerve lesions with easy dissection of the proximal stump of the radial nerve, grafting plus transfer of the pronator quadratus motor branch to the ECRB is now our first choice. If elbow extension reconstruction is needed, grafting is a possibility. Transfer of the thoracodorsal or brachialis nerve to the triceps long and medial head motor branches is another viable alternative. In patients with no PL, an immediate tendon transfer for thumb and finger extension reconstruction might be considered, because this transfer also improves wrist extension. ${ }^{19}$ If reinnervation occurs after grafting, there is no impairment associated with a previous tendon transfer. Indeed, late reinnervation might improve the results of a tendon transfer. ${ }^{13}$

\section{Conclusions}

In proximal radial nerve injuries, the results of nerve grafting for wrist/thumb and finger extension are less than ideal. Combining nerve grafts with either nerve or tendon transfers is what we now recommend.

\section{References}

1. Alnot J, Osman N, Masmejean E, Wodecki P: [Lesions of the radial nerve in fractures of the humeral diaphysis. Apropos of 62 cases.] Rev Chir Orthop Reparatrice Appar Mot 86:143-150, 2000 (Fr)

2. Altintas AA, Altintas MA, Gazyakan E, Gohla T, Germann G, Sauerbier M: Long-term results and the Disabilities of the Arm, Shoulder, and Hand score analysis after modified 
Brooks and D'Aubigne tendon transfer for radial nerve palsy. J Hand Surg Am 34:474-478, 2009

3. Bertelli JA, Ghizoni MF: Nerve transfers for elbow and finger extension reconstruction in midcervical spinal cord injuries. J Neurosurg 122:121-127, 2015

4. Bertelli JA, Ghizoni MF: Results and current approach for brachial plexus reconstruction. J Brachial Plex Peripher Nerve Inj 6:2, 2011

5. Bertelli JA, Ghizoni MF: Transfer of a flexor digitorum superficialis motor branch for wrist extension reconstruction in C5-C8 root injuries of the brachial plexus: a case series. Microsurgery 33:39-42, 2013

6. Bertelli JA, Ghizoni MF: Transfer of nerve branch to the brachialis to reconstruct elbow extension in incomplete tetraplegia: case report. J Hand Surg Am 37:1990-1993, 2012

7. Bertelli JA, Ghizoni MF: Transfer of supinator motor branches to the posterior interosseous nerve in C7-T1 brachial plexus palsy. J Neurosurg 113:129-132, 2010

8. Bertelli JA, Santos MA, Kechele PR, Ghizoni MF, Duarte H: Triceps motor nerve branches as a donor or receiver in nerve transfers. Neurosurgery 61:333-339, 2007

9. Bertelli JA, Tacca CP, Winkelmann Duarte EC, Ghizoni MF, Duarte H: Transfer of the pronator quadratus motor branch for wrist extension reconstruction in brachial plexus palsy. Plast Reconstr Surg 130:1269-1278, 2012

10. Cetin A, Genc M, Sevil S, Coban YK: Prevalence of the palmaris longus muscle and its relationship with grip and pinch strength: a study in a Turkish pediatric population. Hand (NY) 8:215-220, 2013

11. Dabas V, Suri T, Surapuraju PK, Sural S, Dhal A: Functional restoration after early tendon transfer in high radial nerve paralysis. J Hand Surg Eur Vol 36:135-140, 2011

12. Davidge KM, Yee A, Kahn LC, Mackinnon SE: Median to radial nerve transfers for restoration of wrist, finger, and thumb extension. J Hand Surg Am 38:1812-1827, 2013

13. Ferraresi S, Garozzo D, Buffatti P: Common peroneal nerve injuries: results with one-stage nerve repair and tendon transfer. Neurosurg Rev 26:175-179, 2003

14. Flores LP: Reanimation of elbow extension with medial pectoral nerve transfer in partial injuries to the brachial plexus. $\mathbf{J}$ Neurosurg 118:588-593, 2013

15. Flores LP: Transfer of a motor fascicle from the ulnar nerve to the branch of the radial nerve destined to the long head of the triceps for restoration of elbow extension in brachial plexus surgery: technical case report. Neurosurgery 70:E516E520, 2012

16. Flores LP: Triceps brachii reinnervation in primary reconstruction of the adult brachial plexus: experience in 25 cases. Acta Neurochir (Wien) 153:1999-2007, 2011

17. Gao K, Lao J, Zhao X, Gu Y: Outcome after transfer of intercostal nerves to the nerve of triceps long head in 25 adult patients with total brachial plexus root avulsion injury. J Neurosurg 118:606-610, 2013

18. García-López A, Navarro R, Martinez F, Rojas A: Nerve transfers from branches to the flexor carpi radialis and pronator teres to reconstruct the radial nerve. J Hand Surg Am 39:50-56, 2014

19. Gousheh J, Arasteh E: Transfer of a single flexor carpi ulnaris tendon for treatment of radial nerve palsy. J Hand Surg Br 31:542-546, 2006

20. Li Y, Ning G, Wu Q, Wu Q, Li Y, Feng S: Review of literature of radial nerve injuries associated with humeral fractures-an integrated management strategy. PLoS ONE 8:e78576, 2013

21. Li ZM: The influence of wrist position on individual finger forces during forceful grip. J Hand Surg Am 27:886-896, 2002

22. Martínez-Villén G, Muñoz-Marín J, Pérez-Barrero P: Are tendon transfers justified in very old hand radial palsies? J Plast Reconstr Aesthet Surg 65:e293-e296, 2012
23. Millesi H: Nerve grafting. Clin Plast Surg 11:105-113, 1984

24. Nunley JA, Saies AD, Sandow MJ, Urbaniak JR: Results of interfascicular nerve grafting for radial nerve lesions. Microsurgery 17:431-437, 1996

25. Oberlin C, Chino J, Belkheyar Z: Surgical treatment of brachial plexus posterior cord lesion: a combination of nerve and tendon transfers, about nine patients. Chir Main 32:141-146, 2013

26. Pan CH, Chuang DCC, Rodríguez-Lorenzo A: Outcomes of nerve reconstruction for radial nerve injuries based on the level of injury in 244 operative cases. J Hand Surg Eur Vol 35:385-391, 2010

27. Pet MA, Ray WZ, Yee A, Mackinnon SE: Nerve transfer to the triceps after brachial plexus injury: report of four cases. J Hand Surg Am 36:398-405, 2011

28. Plate JF, Ely LK, Pulley BR, Smith BP, Li Z: Combined proximal nerve graft and distal nerve transfer for a posterior cord brachial plexus injury. J Neurosurg 118:155-159, 2013

29. Ray WZ, Mackinnon SE: Clinical outcomes following median to radial nerve transfers. J Hand Surg Am 36:201-208, 2011

30. Ring D, Chin K, Jupiter JB: Radial nerve palsy associated with high-energy humeral shaft fractures. J Hand Surg Am 29:144-147, 2004

31. Roganovic Z, Petkovic S: Missile severances of the radial nerve. Results of 131 repairs. Acta Neurochir (Wien) 146:1185-1192, 2004

32. Ropars M, Dréano T, Siret P, Belot N, Langlais F: Long-term results of tendon transfers in radial and posterior interosseous nerve paralysis. J Hand Surg Br 31:502-506, 2006

33. Shahgholi L, Bengtson KA, Bishop AT, Shin AY, Spinner RJ, Basford JR, et al: A comparison of manual and quantitative elbow strength testing. Am J Phys Med Rehabil 91:856862,2012

34. Shergill G, Bonney G, Munshi P, Birch R: The radial and posterior interosseous nerves. Results of 260 repairs. J Bone Joint Surg Br 83:646-649, 2001

35. Soldado F, Ghizoni MF, Bertelli J: Thoracodorsal nerve transfer for triceps reinnervation in partial brachial plexus injuries. Microsurgery [epub ahead of print], 2015

36. Suzuki T, Kunishi T, Kakizaki J, Iwakura N, Takahashi J, Kuniyoshi K: Wrist extension strength required for power grip: a study using a radial nerve block model. J Hand Surg Eur Vol 37:432-435, 2012

37. Terzis JK, Konofaos P: Radial nerve injuries and outcomes: our experience. Plast Reconstr Surg 127:739-751, 2011

38. van Zyl N, Hahn JB, Cooper CA, Weymouth MD, Flood SJ, Galea MP: Upper limb reinnervation in C6 tetraplegia using a triple nerve transfer: case report. J Hand Surg Am 39:1779-1783, 2014

\section{Disclosure}

The authors report no conflict of interest concerning the materials or methods used in this study or the findings specified in this paper.

\section{Author Contributions}

Conception and design: Bertelli. Acquisition of data: both authors. Analysis and interpretation of data: both authors. Drafting the article: Bertelli. Critically revising the article: both authors. Reviewed submitted version of manuscript: Bertelli. Approved the final version of the manuscript on behalf of both authors: Bertelli.

\section{Correspondence}

Jayme A. Bertelli, Rua Newton Ramos 70, apto 901, Florianópolis-SC, 88015395, Brazil. email: drbertelli@gmail.com. 